\title{
ASPARAGUS ILARVIRUS 2 (AV2) TRANSMISSION IN ASPARAGUS SEED
}

\author{
M.V. JASPERS ${ }^{1}$ and M.N. PEARSON ${ }^{2}$ \\ ${ }^{1}$ Soil, Plant and Ecological Sciences Division, Lincoln University, Canterbury \\ ${ }^{2}$ School of Biological Sciences, University of Auckland, Auckland
}

Asparagus ilarvirus 2 (AV2), which is widespread in asparagus crops throughout the world, has been shown to cause reductions of up to $57 \%$ in yield of asparagus spears. The virus has been reported to spread rapidly through asparagus crops in sap on harvesting knives, to be transmitted via seed and to be present on pollen from AV2infected male plants. The parental source of AV2 in infected seed was investigated by hand cross-pollination between AV2-infected and AV2-free parent plants of each gender. ELISA tests of shoots from the resulting seedlings showed that AV2 was transmitted into $95 \%$ of seedlings when both parents were infected, and into $17 \%$ and $47 \%$ of seedlings respectively, when only the male or female parent was infected. Infection of either or both parents resulted in reduced success of pollination. The size and number of the resulting seed, its germination and seedling viability were also reduced. Primary spread of AV2 into new asparagus plantings is likely to be by infected seed, and into existing, virus-free asparagus plantings may be by infected pollen. The female flowers fertilised with AV2-infected pollen may produce infected seed and volunteer seedlings, which can act as sources for mechanical spread of the virus within crops.

\section{FORECASTING BARLEY YELLOW DWARF VIRUS IN CANTERBURY WINTER-SOWN CEREALS}

\author{
D.A.J. TEULON and M.A.W. STUFKENS
}

\author{
NZ Institute for Crop \& Food Research Ltd, Private Bag 4704, \\ Christchurch, New Zealand
}

In Canterbury, New Zealand, autumn-sown cereals are usually sown after midMay (emerging after June 1) to avoid autumn flights of up to 6 aphid species which transmit the debilitating barley yellow dwarf virus (BYDV). However, occasionally aphid flights continue into June and July causing severe BYDV infestations. Based on nine years of $7.5 \mathrm{~m}$ high suction trap catches at Lincoln, Canterbury, a significant relationship between aphid numbers trapped in June and July and the proportion of crops with economic infestations $(>5 \%)$ of BYDV has been developed. Severe BYDV incidence can be predicted in August allowing appropriate pest management actions to be taken. With financial support from the Foundation for Arable Research and the Agricultural Marketing Research and Development Trust and practical support from cereal growers, aphid monitoring was extended in 1997-98 with new suction traps in Hilton (South Canterbury) and Rokeby (Mid Canterbury). From April to July, numbers of BYDV aphid vectors are counted from suction traps and made available to growers on a weekly basis through an Internet site (http://www.crop.cri.nz/news/ aphid/index.htm) and a prerecorded phone message. A forecast of BYDV incidence is also published in local newspapers in August. 